\title{
Fostering Net Promoter Score: Crafting User Experience in Difference Cultural Ecosystem
}

\author{
Leonardus W Wasono Mihardjo, Sasmoko, Riza A.N. Rukmana
}

\begin{abstract}
The customer research in terms of usability, usefulness and branding on User Experience (UX) design is a critical part of the success in application implementation on Information communication technology (ICT) industry. The study on impact of cultural system with similar target market into designing $U X$ in correlation with net promoter score (NPS) has not been revealed as part of important factor, for designing and evaluation of application design. Hence, this paper has objective to assess the effect of user experience (UX) in difference cultural ecosystem in relation with NPS for Indonesia diaspora. The case of prepaid product Kartu As 2 in1 was investigated. The survey done through discussion with 20 respondents of Indonesia diaspora, with 10 respondents in Indonesia and Malaysia respectively. The result found that there is some similarity pattern of customer characteristics. However, some variations due to cultural ecosystem difference is found, that the Indonesia diaspora living in Malaysia mostly focused on the easiness of the use, but in Indonesia, they focused on the functionality
\end{abstract}

Index Terms: user experience, cultural ecosystem, net promoter score, Indonesia diaspora, Telin

\section{INTRODUCTION}

The customer research is an important part on the design of application. The intensive research based on observation and interview of customers are needed to explore and analyse the insight about customers. The customer's insight become an input for application designers to design user interfaces to focus on usability, usefulness and leveraging firm brand to deliver a smooth user interaction (Chincholle, Lachize, Backstrom, \& Eriksson, 2013). User experience (UX) designers are concerned on the interaction of cognitive, physical, easiness and behavioural of users (Romeo, Karreman, Pietro Romeo, \& Li, 2017). Hence, the cultural ecosystem plays significant role to drive user perception of UX.

The previous study about cultural difference have been conducted on area usability with unit analysis of customer with different backgrounds and nationalities (Konstantakis, Michalakis, Aliprantis, Kalatha, \& Caridakis, 2017; Romeo et al., 2017; Santoso, Schrepp, Hinderks, \& Thomaschewski, 2017), however the study of the effect of ecosystems in impacting to the culture with unit analysis of customers that having similar background who live in different countries has not been conducted, as well as in relationship between UX with NPS impact (Følstad \& Kvale, 2018). Hence, The goal of the study is to investigate the impact of cultural ecosystem of Indonesia diaspora who have different impressions in Malaysia and Indonesia in designing UX to improve NPS and user experience of products. The case of prepaid application of Mobile Virtual Network (MVNO) from Telkom Indonesia International (Telin) called as Kartu As 2in1 was used to assess the impact of cultural ecosystems.

The findings of this study have theoretical implications in strengthening the knowledge of the impact of culture in designing UX and NPS, and in practice the findings could improve the design of the prepaid application. In the paper we will describe literature review, methodology, findings, and then discussions and conclusions.

\section{LITERATURE REVIEW}

\section{A. Cultural Difference Indonesia and Malaysia}

Two Countries has similarity in terms of culture, resources and heritage, however Malaysia is more advanced in terms of economic growth and competitiveness compared to Indonesia. Thompson et al (2007) studied a comparison between Indonesia and Malaysia, relative to other countries. The study observed Indonesia and Malaysia students and found that students of Malaysia was distinct with Indonesia in terms of knowledge, but Indonesia and Malaysia are quite similar due to the same religious background as shown in Figure 1.

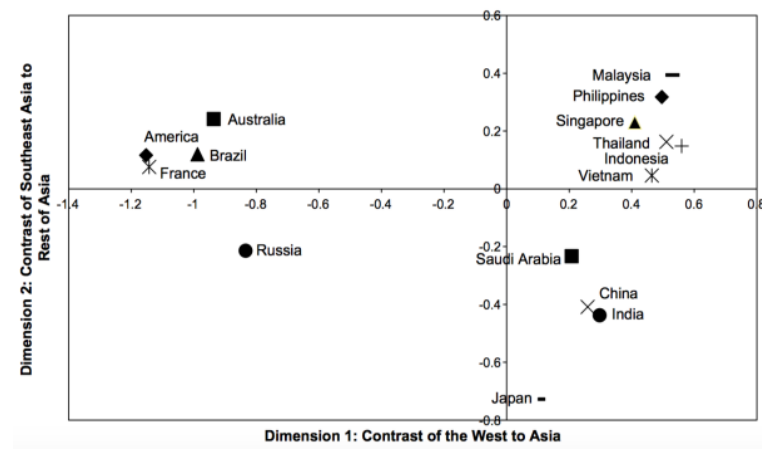

Revised Manuscript Received on September 22, 2019.

Leonardus W Wasono Mihardjo, School of Business, Bina Nusantara University, Jakarta, Indonesia.

Sasmoko, Primary Teacher Education Departmeny, Bina Nusantara University, Jakarta, Indonesia. Email: sasmoko@binus.edu

Riza A.N. Rukmana, Industrial Engineering Department, Telkom University, Bandung, Indonesia. 


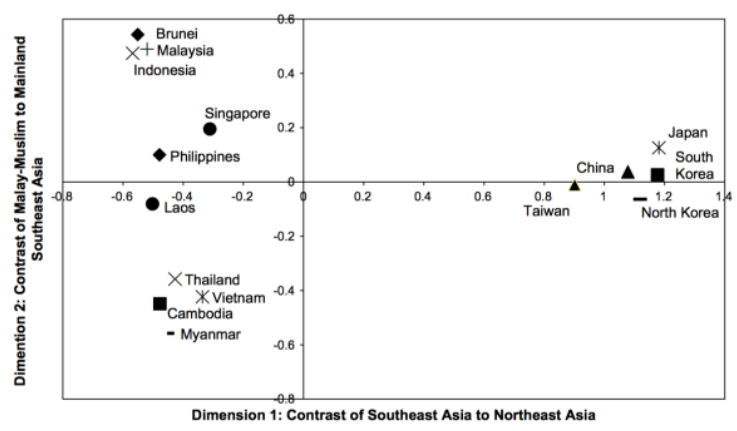

Figure 1. Mapping Indonesia-Malaysia Cognitive mapping comparison

(Thompson, Thianthai, \& Hidayana, 2007)

The difference of knowledge as mentioned in Figure 1 was derived from the differences of competitiveness environment, where Malaysia has better competitiveness in all aspect except in market size as shown in table 1, especially in infrastructure, ICT adoption, human capital and innovation ecosystem. The previous studies show that culture ecosystems affected the perception cognitive and behaviour of customers in certain market area (Kastanakis \& Voyer, 2014), and some policies related with different cultures has been taken since in reality Indonesia and Malaysia are having different cultures and perceptions (Lubis, 2017). While in designing of User experience, the overall designs are based on impression and perception of users (Konstantakis et al., 2017; Romeo et al., 2017). Hence, the cultural ecosystem is critical factors in designing UX, even though the target market has similar background.

Table 1. Indonesia vs Malaysia Competitiveness 2018

(Malaysia Competitive Corporation, 2018)

\begin{tabular}{|c|c|c|}
\hline & Indonesia & Malaysia \\
\hline \multicolumn{3}{|l|}{ Overall Rank } \\
\hline Overall Rank & 45 & 25 \\
\hline Score & 64.9 & 74.4 \\
\hline \multicolumn{3}{|l|}{ Enabling environment Rank } \\
\hline Institution Rank & 48 & 24 \\
\hline Infrastructure Rank & 71 & 32 \\
\hline ICT Adoption rank & 50 & 32 \\
\hline Macroeconomic Stability rank & 51 & 1 \\
\hline \multicolumn{3}{|l|}{ Human Capital Rank } \\
\hline Health & 95 & 62 \\
\hline Education and skill & 62 & 24 \\
\hline \multicolumn{3}{|l|}{ Market Rank } \\
\hline Product market Rank & 51 & 24 \\
\hline Labour market rank & 82 & 20 \\
\hline Financial system rank & 52 & 15 \\
\hline
\end{tabular}
Figure 2. usability were required to be explored.

\section{User experience} the task , (2) efficiency: how fast the users to accomplish the task (3) memorability where the application is easy

Kartu As 2in1 is a Telkom Indonesia international product on Mobile Virtual network prepaid who serves Indonesia diaspora who work or live overseas. The product could provide double side mobile number which are virtual number of Indonesia mobile number and overseas mobile number. Hence, the customers could enjoy the benefit of domestic charges in Indonesia and overseas. The MVNO service covers 4 overseas countries: Malaysia, Hongkong, Taiwan and Macau (Telin, 2019). The development of Kartu As 2in 1 was an enhancement of existing product to enable global connectivity of the service, hence it brings convenience to Indonesia diaspora who can access the service whereever they stay as long as they could connect to Internet and can be downloaded at Google Play and App Store as shown in

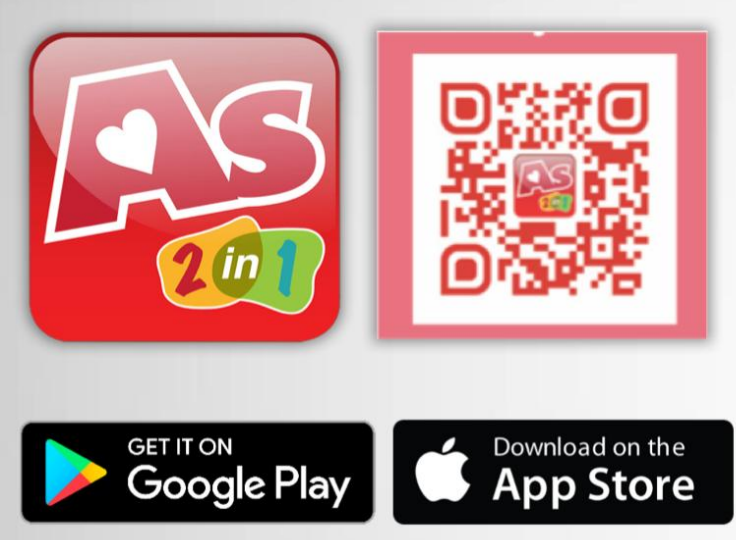

Figure 2. kartu As 2in1 applications

The advantages of Kartu As 2in1 applications were as follows: it became global since it was not dependent on the agreement with mobile network operators, a rich feature and Indonesian content such as movies, games, and other features such as credit transfer, mobile payment for electricity, telephone and mobile wallet, and since it has Indonesia number, it has cheaper international Direct Dialling (IDD). Those features and facilities were designed in web application where the customer survey regarding the

The use of customer research is to increase the use of data traffic by designing the content and application based on UX (Hussain, 2013). UX is multidimensional and has been widely used for evaluating experience to improve the particular product. Jacob Nielsen (2002) has five attributes in designing UX: (1) learnability: how easy the user to perform

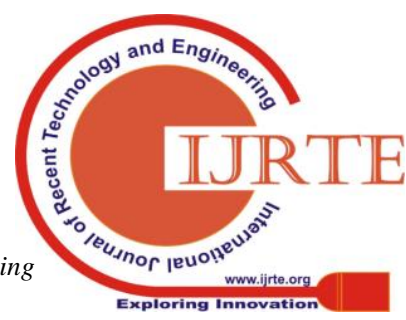


for the user to remember the task. (4) errors : how often the user perform errors in the use application and how they could improve(5) satisfaction of user after evaluation and improvement of application. Hence, the design shall involve the attitude and behaviour of customer that could accommodate in multicultural perspective (Konstantakis et al., 2017). The five attributes reflects the utility which is providing features that customers need. The combination between the utility and usability creates useful applications (Nielsen, 2012).

UX design involves a person's attitude, behaviour and emotions of users and appears as the part of culture dimension, called as cultural user experience (Konstantakis et al., 2017). The engagement of customers could trigger cultural of organization to create co-creation value with the customer as part of the customer's journey as shown the value creation model in Figure 3 (Vincenza Ciasullo, Troisi, \& Cosimato, 2018).

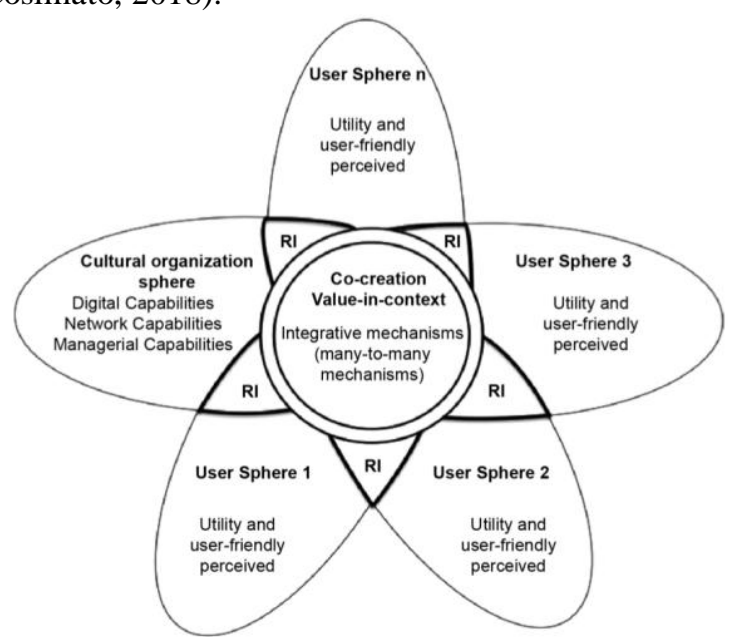

Figure 3. Cultural digital Co-creation Value (Vincenza Ciasullo et al., 2018)

Thus, based this study, it could be revealed how the role the technological advancement and the digital tools based on user experience have deeply changed the processes of culture organizations to leverage service systems, integrate people, technologies, processes and information in order to create mutual benefits.

\section{Net Promoter Score}

Net Promoter Score (NPS) gathers information from customer to get the feedback on the value chain in creating service to customer. The main purpose of the NPS is to get the input for management to take actionable metric for service managers in all process including the digital application design. NPS is typically implemented as a brief questionnaire survey following a service process. Customers are asked a quantitative question on their likelihood to recommend (LTR) the service provider on a scale from 0 to 10 The NPS has been demonstrated to be a measurement tool of customer experience and customer loyalty to boost revenue growth (Keiningham, Cooil, Andreassen, \& Aksoy, 2007). To make NPS score actionable, insight is needed on the drivers of customer experience which motivate the customers to give their scores and their main reason for their score to provide feedback to the firm. To achieve the objective of NPS the correct respondents become a critical issue (Fisher \& Kordupleski, 2018). of service companies. With the proper implementation, NPS could demonstrate that it is able to provide customer insight to improve organizational growth (Rajasekaran \& Dinesh, 2018).

\section{METHOD}

The method to capture the feedback from user insight of the product in relation with the usefulness, usability, efficiency, pleasant \& easiness to use, learnability to remember; and consistent with better look and feel design, is to use the iteration approach as illustrated in Figure 4.

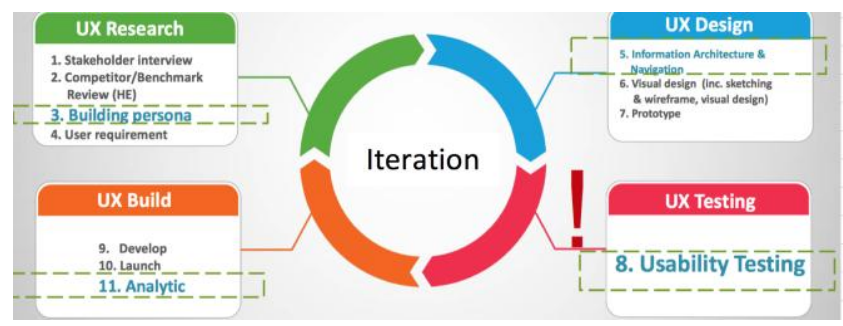

Figure 4. Iteration Design Methods

To implement this strategy, there were 4 process model from UX research, UX design, UX build and UX testing (Nielsen, 2012). UX research for the initial process need to be developed to build personal service align with the cultural ecosystem that may differ between Indonesia and Malaysia. UX design needs to be built to ensure the information architecture and navigation align with the objective of UX design to match product apps design with the customer experience in terms of usefulness, usability, efficiency, pleasant \& easiness to use, learnability to remember and pleasant. UX build and testing to be done to assure the UX design can work properly and can be provided the feedback and evaluation for management to improve the future design development. The holistic implementation framework and methods in collecting data can be shown in Figure 5. The scope of test covered all features and application designs for Kartu As 2in1 from customer who uses Kartu As 2in1 in Malaysia and Indonesia. Cross-functional teams was involved not only from observer and facilitators but also from Information technology team to get understanding of users, business goals and technology possibilities. The sample in Malaysia was taken from the customers living in Petaling Jaya and Gombak where Indonesian diaspora have large community and intensively interact with Malaysian community. While Indonesian samples were taken from East Java where most Indonesian diaspora came from especially in Surabaya and Sidoarjo. Total 20 samples were taken with 10 samples were from Malaysian and Indonesian

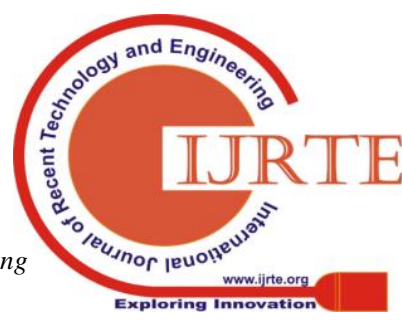


users, respectively.

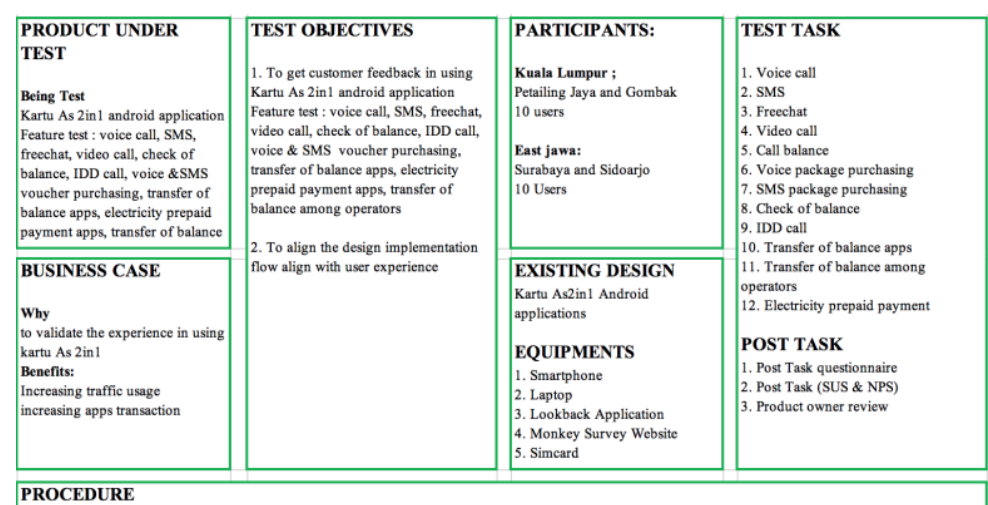

PROCEDURE

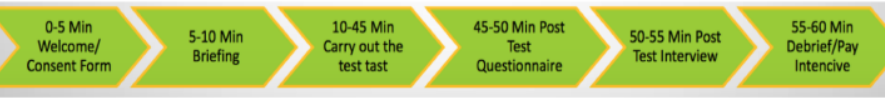

*SUS: System Usability Scale, NPS : Net Promoter Score

Figure 5. Method and Procedure Collecting Data

The procedure for taking data took 60 minutes in average, started from welcome consent and briefing, then test questionnaire and debrief pay intensive.

\section{Result}

The comparison result of completion rate and single easy question test between diaspora Indonesia in Malaysia and Indonesia can be shown in Table 1. The completion rate indicates the users accomplishment task in certain time and single easy question (SEQ) is questionnaire result of the user perception when using the applications.

Table 1. The Result of Completion Rate and SEQ

\begin{tabular}{|r|l|c|c|c|c|}
\hline \multirow{2}{*}{\multicolumn{2}{|c|}{ Test Items }} & \multicolumn{2}{c|}{ Malaysia } & \multicolumn{2}{c|}{ Indonesia } \\
\cline { 3 - 6 } & $\begin{array}{c}\text { Completion } \\
\text { Rate }\end{array}$ & $\begin{array}{c}\text { Single } \\
\text { Easy } \\
\text { Question }\end{array}$ & $\begin{array}{c}\text { Completi } \\
\text { on Rate }\end{array}$ & $\begin{array}{c}\text { Single } \\
\text { Easy } \\
\text { Questi } \\
\text { on }\end{array}$ \\
\hline 1 & Voice call & $0 \%$ & 4 & $0 \%$ & 5 \\
\hline 2 & SMS call & $50 \%$ & 4.6 & $50 \%$ & 5.5 \\
\hline 3 & Free chat & $20 \%$ & 2.8 & $20 \%$ & 4 \\
\hline 4 & Video Call & $0 \%$ & 3.5 & $0 \%$ & 2 \\
\hline 5 & Check of balance & $70 \%$ & 5.5 & $70 \%$ & 6 \\
\hline 6 & $\begin{array}{l}\text { Voice package } \\
\text { purchasing }\end{array}$ & $70 \%$ & 5.5 & $60 \%$ & 4.5 \\
\hline 7 & $\begin{array}{l}\text { SMS package } \\
\text { purchasing }\end{array}$ & $70 \%$ & 4.8 & $60 \%$ & 4.8 \\
\hline 8 & IDD Call & $80 \%$ & 6.3 & $80 \%$ & 6.5 \\
\hline 9 & $\begin{array}{l}\text { Transfer balance } \\
\text { apps }\end{array}$ & $70 \%$ & 4 & $50 \%$ & 3 \\
\hline 10 & $\begin{array}{l}\text { Transfer balance } \\
\text { Operators }\end{array}$ & $70 \%$ & 4.5 & $50 \%$ & 5 \\
\hline 11 & Prepaid electricity & $10 \%$ & 3 & $10 \%$ & 4 \\
\hline
\end{tabular}

Based on the data The System Usability Score, the result ws that the score of Indonesia diaspora in Malaysia was while score in Indonesia was 39\% less than expected score on 68\% and NPS score for diaspora Indonesia in Malaysia and Indonesia was 0 and $10 \%$ respectively less than average NPS application was $31 \%$ (Telin, 2019)

\section{Discussion}

Our findings indicate that there are differences between the perception of user experience between Indonesians who are living in Malaysia and Indonesia. Both groups differ in the judgement of the products concerning the quality aspects and the functionality aspect as impact of ecosystem's influence. Clearly differences concerning the quality of the interface design have impact on experience as well as the functionality design. With the completion rate of Malaysia is higher and NPS score is lower, it indicates that diaspora who have lived in better ecosystem in term of economics required more experience expectation and require more quality rather than functionality, while Indonesian user in Indonesia tended to judge the importance of pragmatic required the functionality of applications for both evaluated products.

For overall, the findings showed that even though Indonesian diaspora have different results, overall result of SUS and NPS was still below the average, indicates that there are still improvements required to boost the performance in terms of revenue. In terms of application improvement, since the result of Indonesian diaspora who are living in Malaysia and Indonesia were almost similar in terms of the feature application item improvement, the enhancement of the application for Malaysian market can be applied for Indonesian market as shown in Figure 6.

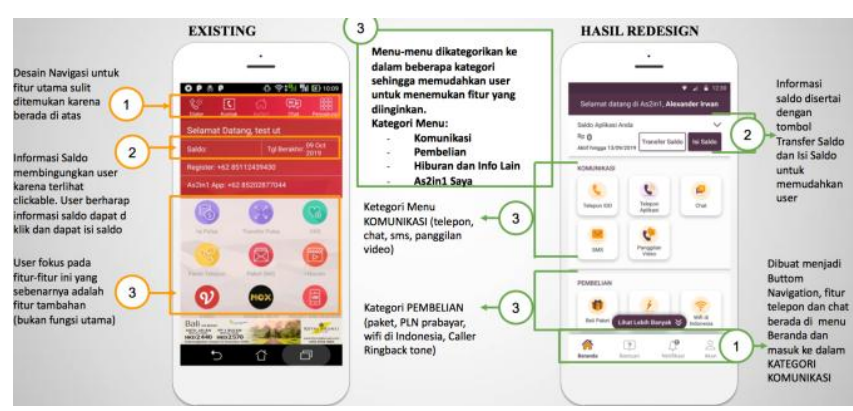

Figure 6. Application Improvement as impact UX Test

\section{Result}

These findings suggest that management who has products for Indonesian diaspora in Indonesia and Malaysia should improve the application and market for both countries in similar fashion. The contribution of theory is related with the concept of international marketing strategy (IMS) decisions, which are influenced by perceived cultural and business distance between their home- and foreign country and influence of cultural ecosystem. The 
previous finding of Indonesian diaspora shown that the greater the physical distance perceived, the higher the degree of IMS adaptation (Hapsari, Stoffers, \& Gunawan, 2017).

\section{Conclusions}

There is an impact of cultural ecosystem in driving the perception of customer to develop the customer experience. Malaysia focuses on the style and easiness, and Indonesia focuses on the functionality of service, however since the respondent stay has no longer in the particular country the overall significant design has not impact to application design. The further study can be focused on the identification of the impact of concrete cultural aspects that influence the expectations of users towards product interfaces and for longitudinal cultural ecosystem impact in designing UX.

\section{ACKNOWLEDGEMENT}

The author acknowledges the work of Telkom University, the assistance of Bengris Pasaribu and team as well as Telin Management, for their assistance and collaboration in contributing to data collection and provide feedback design of application for Kartu As2in1

\section{REFERENCES}

1. Chincholle, D., Lachize, S., Backstrom, C., \& Eriksson, C. (2013). Crafting UX - designing the user experience beyond the interface. Ericsson Review, 7(2013), 1-8. Retrieved from https://www.ericsson.com/res/thecompany/docs/publications/ericsson_re view/2013/er-crafting-ux.pdf

2. Fisher, N. I., \& Kordupleski, R. E. (2018). What ' $s$ Wrong with Net-Promoter Score?

3. Følstad, A., \& Kvale, K. (2018). Using the Net Promoter Score to support service design: Digging for gold in customer free-text reports. In Service Design Proof of Concept (pp. 512-527).

4. Hapsari, C., Stoffers, J., \& Gunawan, A. (2017). International Review of Management and Marketing The Influence of Perceived Cultural and Business Distance on International Marketing Strategy Decisions; A Case Study of Telkom Indonesia International. International Review of Management and Marketing, 7(3), 238-245. Retrieved from http:www.econjournals.com

5. Hussain, M. (2013). Collaborative Innovation and User Experience Control- Strategies for Monetization of QoS of Data by Cellular Operators. Massachusetts institute of Technology.

6. Kastanakis, M. N., \& Voyer, B. G. (2014). The effect of culture on perception and cognition: A conceptual framework. Journal of Business Research, 67(4),

425-433. https://doi.org/10.1016/j.jbusres.2013.03.028

7. Keiningham, T. L., Cooil, B., Andreassen, T. W., \& Aksoy, L. (2007). A Longitudinal Examination of Net Promoter and Firm Revenue Growth Journal of Marketing, 71(3), 39-51. https://doi.org/10.1509/jmkg.71.3.39

8. Konstantakis, M., Michalakis, K., Aliprantis, J., Kalatha, E., \& Caridakis, G. (2017). Formalising and evaluating Cultural User Experience. Proceedings - 12th International Workshop on Semantic and Social Media Adaptation and Personalization, SMAP 2017, 90-94. https://doi.org/10.1109/SMAP.2017.8022675

9. Lubis, Z. (2017). The comparison between Indonesia and Malaysia Tourism Performance, Policies and Sources. The Social Sciences, 12(9), 1646-1657.

10. Malaysia Competitive Corporation. (2018). Malaysian in the Global Competitive Report 2018.

11. Nielsen, J. (2012). Usability 101: Introduction to Usability Why Usability is Important.

12. Rajasekaran, M. N., \& Dinesh, M. N. (2018). How Net Promoter Score Relates To Organizational Growth. International Journal of Creative Research Thoughts, 6(2), 2320-2882. Retrieved from www.ijcrt.orgwww.ijcrt.org

13. Romeo, P., Karreman, J., Pietro Romeo, U., \& Li, Q. (2017). Cross-Cultural HCI and UX Design: A Comparison of Chinese and
Western User Interfaces Cross-Cultural HCI and UX Design: A Comparison of Chinese and Western User Interfaces Investigating cultural factors behind WeChat and its Western counterparts. https://doi.org/10.13140/RG.2.2.18547.63525

14. Santoso, H., Schrepp, M., Hinderks, A., \& Thomaschewski, J. (2017). Cultural Differences in the Perception of user experience. Korean Publishing Science Society, 77(September), 267-271. https://doi.org/10.21732/skps.2017.77.111

15. Telin. (2019). Annual Report Telin 2018: Securing the rebound through Business innovations, infrastructure expansion and Transformation towards Global Digital Hub.

16. Thompson, E. C., Thianthai, C., \& Hidayana, I. (2007). Culture and international imagination in Southeast Asia. Political Geography, 26(3), 268-288. https://doi.org/10.1016/j.polgeo.2006.10.011

17. Vincenza Ciasullo, M., Troisi, O., \& Cosimato, S. (2018). How Digital Platforms Can Trigger Cultural Value Co-Creation?-A Proposed Model. Journal of Service Science and Management, 11(02), 161-181. https://doi.org/10.4236/jssm.2018.112013

\section{AUTHORS PROFILE}

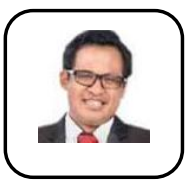

First Author Leonardus W Wasono Mihardjo is a Doctor candidate in Management at Bina Nusantara University, West Jakarta, Indonesia. His research has attracted funding award from Indonesia Ministry of research and higher education in 2019, as well as awarded as best paper in Malaysian conference 2018. Currently, he is a director of Financial and Business Partner at PT Telekomunikasi Indonesia International (Telin) focus on financial and development of Human capital. He is also chairman of PT Telin Australia and Board member of Telin Singapore. He has more than 20 years in Telecommunication Industry with 12 years in Telkomsel. His research interest includes digital transformation, business model innovation, technology, digital leadership and strategic management Orcid ID ; orcid.org/0000-0002-3820-4960

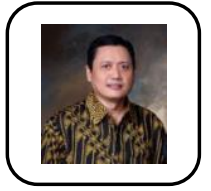

\section{Second Author Sasmoko}

Sasmoko is a Professor of Research Methods of Faculty of Humanities at Bina Nusantara University, Jakarta. He is currently working at the RIG-Education Technology, Binus University. Their most recent publication is 'Applying indonesian teacher engagement index (ITEI) apps: Self-diagnostic apps for teachers in Indonesia', including the use of Artificial Intelligent for education and social Science. His researches have attracted funding award from Indonesia Ministry of research and higher education and also from Bina Nusantara university.

His research interest includes teaching methods, teacher education and educational assessment, including the use of Technology for Education Orcid ID: orcid.org/0000-0001-9219-9237

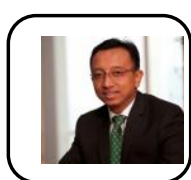

Third Author Dr. Riza A.N. Rukmana is currently a senior lecturer of Telkom University, a leading university in Indonesia focusing on telecommunication related studies. $\mathrm{He}$ is also Vice President of Marketing and Business Intelligence at PT Telkom Indonesia International (2015-current). He has more than 22 years experiences in Indonesia telecommunication industry. He joined Telkom Indonesia International since 2011 as a VP of Corporate Strategic Planning (2011-2015). Before that he was a Telkom employee since 1996 to 2011 . He earned his bachelor's in industrial engineering from STT Telkom in 1995 and master's degree on Marketing Management from Padjajaran University, Bandung, Indonesia in 1998, Dr. Riza completed his Ph.D. in Management and Economics Studies at Padjajaran University, Bandung, Indonesia in 2005. He has numerous consulting experiences in Strategy Formulation and Market Research 